DOI: $10.22616 /$ REEP.2020.027

\title{
Mathematical Modelling as a Means of Formation of Methodical Competence of the Prospective Teacher
}

\author{
Bakhytkul Kaskatayeva ${ }^{1}$ Doctor of pedagogy; Maral Andassova ${ }^{2} \mathrm{PhD}$ \\ Kazakh National Women`s Teacher Training University, Kazakhstan ${ }^{1}$ \\ Kazakh Ablai Khan University of International Relations and World Languages, Kazakhstan ${ }^{2}$ \\ Kaskataeva1946@gmail.com ${ }^{1}$; andassova872@gmail.com ${ }^{2}$
}

\begin{abstract}
In this article the method of formation of methodical competence of students of pedagogical university is developed. The task of the higher school is to raise a new generation of professionally competent mathematics teachers. In this regard, there is a need to develop effective methods of training prospective teachers. The aim of the study is to develop a methodology for the use of mathematical modelling for the formation of methodical competence of the prospective teacher. The study used research methods such as theoretical analysis of scientific literature, observation, generalization. As a result, a method of using mathematical modelling as a means of forming the methodological competence of the prospective teacher was developed. Every method of scientific research, both theoretical and experimental, is based on the method of modelling, since in sign modelling, models appear in the form of graphs, drawings, formulas, systems of equations, sentences in natural or artificial (symbols) language.
\end{abstract}

Keywords: mathematical modelling, methodical competence, mathematics teachers, pedagogical university education.

\section{Introduction}

The task of the higher school is to raise a new generation of professionally competent teachers in accordance with the modern model of education of Kazakhstan in the conditions of digitalization. In this regard, there is a need to develop effective methods of training future professionally competent teachers.

Currently, a special role is given to the competence approach, which is in demand in domestic and foreign school systems. The competence approach meets the state ideology and acts as a means of updating the educational policy of Kazakhstan. The need for the introduction of competence approach in Kazakhstan is defined in the State program of education development of the Republic of Kazakhstan for 2011-2020 (State program of..., 2010).

The analysis of domestic and foreign literature on the formation of methodical competence of the prospective teacher showed that the relevance of this problem is determined not only by the social order, but also by the student's needs for self-determination and self-expression (Trede, Macklin, Bridges, 2012). Special attention of foreign and domestic researchers points to the lack of knowledge of students on the problem of methodical competence in the process of studying at the university, as well as contradictions between the need of educational institutions in competent specialists and their lack of theoretical and practical training. In this regard, there is a need to train competitive teachers who have the necessary important qualities, knowledge and skills, able to adapt independently and quickly in a constantly changing information and technological environment, that is, to develop their skills having professional competence, the main component of which is methodical competence. The works of scientists (Tang, Wong, Cheng, 2015; Boud, Molloy, 2013; Briede, Krastina, 2006; Briede, Pēks, 2014) revealing the main provisions of the competence approach are important in this regard; as well as pedagogical conditions of forming the research competence masters are identified (Kaskatayeva, 2014). Vocational training is the process of acquiring skills that are necessary to carry out certain duties related to a job or group of jobs (Kaskatayeva, 2009).

The main components of the teacher's professionalism, his/her pedagogical skills are professional competence, creativity, culture, technology, individual style, innovative and research approach to activity, its productivity. The highest stage of professional competence is manifested in a teacher with experience, but its prerequisites and individual components are formed during training in a pedagogical university. Professional competence of the teacher is a multifactorial phenomenon that includes a system of theoretical knowledge of the teacher and ways of their application in specific pedagogical situations, 
value orientations of the teacher, as well as integrative indicators of his/her culture (speech, communication style, attitude to himself and his activities, to related areas of knowledge).

Professional competence is understood as a set of professional and personal qualities necessary for successful pedagogical activity. Professional competent can be called a teacher who at a sufficiently high level carries out pedagogical activities, pedagogical communication, achieves consistently high results in development and education (Kaskatayeva, 2018a).

The final frontier in the professional training of future specialists is the formation of their professional competence. Methodical competence is the main component of professional competence of the teacher. The authors had previously identified the essence of the concept of methodical competence, "as personal professional qualities that allow achieving a methodological result, its theoretical and practical readiness to teach the subject and possession of modern technology of training" and justified that methodical competence is the main component of professional and pedagogical competence of the teacher (Kaskatayeva, 2018b).

In previous studies, the authors had also developed interactive methods for the formation of methodological and research competencies (Kaskatayeva, 2017; Kaskatayeva, Andassova, Andassov, 2018). The subject of further study is the search for effective methods of formation of MC. One of effective methods of formation of methodical competence of the prospective teacher is mathematical modelling which develops independent effective thinking, intelligence. Modelling, as analysis, abstraction, generalization, induction, analogy, refers to General logical methods and techniques of research.

Modelling is a method of studying certain objects by reproducing their characteristics on another objecta model that is an analogue of a particular fragment of reality (real or mental) - the original model. There must be a certain similarity (similarity) between the model and the object of interest to the researcher - in physical characteristics, structure, and functions. Any method of scientific research, both theoretical and experimental, is based on the method of modelling, since in sign modelling, models appear in the form of graphs, drawings, formulas, systems of equations, sentences of natural and artificial (symbols) language. Currently, mathematical (computer) modelling is widely used.

Mathematical modelling is the art of translating problems from an application area into tractable mathematical formulations whose theoretical and numerical analysis provides insight, answers, and guidance useful for the originating application.

Several scientist's has the previous experience of studies about mathematical modelling: - about student strategies to mathematical modelling, instructional implementation of mathematical modelling, and assessment of these activities (Lyon, Magana, 2020); about modelling of online short-courses for teaching mathematics for prospective primary school teachers (Jackson et al., 2020); mathematical modelling opportunities of secondary school teachers (Jung, Stehr, He, 2019; Hernandez-Martinez et al., 2019; Tran et al., 2019); the analysis of the modelling processes that emerged during the implementation of a didactic sequence of Inquiry-Based Mathematics Education - their methodology basically consists of finding evidence in the implementation that reveals the emergence of some of the sub-processes from the modelling model (Sala, Font, 2019). S. Bernander, J.E. Szydlik, C.E. Seaman focuses on ways to foster and model a classroom culture of doing mathematics with prospective teachers, to develop mathematical thinking, supporting students in problem solving, using precise language and notation, making sense of definitions, conjecturing and generalizing (Bernander, Szydlik, Seaman, 2020).

Today the method of formation of methodical competence of students by means of mathematical modelling is insufficiently developed. In this regard, there is a need to develop methodical of using mathematical modelling in order to increase the level of professional readiness of students of pedagogical university, which predetermined the relevance of this topic.

Analysing the findings of the aforementioned scientists, the authors define mathematical modelling as a method of qualitative and quantitative description of the process using a mathematical model, which describes the real process using an adequate mathematical technique.

The aim of the study is to develop a method of using mathematical modelling as a means of forming the methodical competence of the prospective teacher. 


\section{Methodology}

The task of the study: to develop a methodology for the formation of methodical competence of the prospective teacher with the help of mathematical modelling in the process of teaching mathematics.

Research methods: study and theoretical analysis of domestic and foreign literature on the problem of research; analysis and generalization of advanced pedagogical experience; generalization and synthesis of empirical material.

It is known that the solution of specific practical problems is carried out by creating its mathematical model. The authors considered mathematical modelling in teaching students in mathematical modelling of applied problems in the practical classes of the course Methods of Teaching Mathematics in high school. In the educational process, much attention should be paid to the methods and techniques of teaching courses, equipment, rational organization of independent work of students. When carrying out theoretical and practical training of prospective teachers, the formation of methodical competence of the prospective teachers is carried out by showing the use of the considered educational material in the future profession.

Focus is on the use of mathematical modelling in the formation of components of methodical competence. When considering the application of mathematical modelling, prospective teachers realized its role for systematization and consolidation of knowledge.

\section{Results and Discussion}

The purpose of the article is to show the theoretical and practical preparation of students for the use of mathematical modelling in the course Methods of Teaching Mathematics. One of the features of the development of science at the present stage is the widespread use of mathematical methods and computer technology in the study of various fields of science. They have a special place in the course of mathematical programming or effective planning models.

Linear programming is a deterministic method to achieve the optimum outcome (such as maximum profit or lowest cost) in a given mathematical model for a set of constraints. It is based on a mathematical technique following three methods: a graphic solution, an algebraic solution and the use of the simplex algorithm (Réveillac, 2015).

Modelling is understood as the study of objects with the help of a model, the construction and study of a model of substances and phenomena of real life (chemical, physical, biological, social processes). Modelling is connected with the process of education development. It has been used since an early time. For example: Brunelleschi, Michelangelo and other Italian architects and sculptors used models of highrise structures that they built. Galileo and Leonardo da Vinci used not only models, but also studied their used places. Subsequently, Newton more deeply showed the application of this method (Cooke, 2013).

A mathematical model is the "equivalent" of an object, reflecting in mathematical form its most important properties the laws to which it obeys, the connections inherent in its constituent parts, there is a triad "model-algorithm-program". "By creating the triad "model - algorithm - program", the researcher gets a versatile, flexible and inexpensive tool in his hands, which is initially debugged, tested in trial computational experiments. After the adequacy (sufficient correspondence) of the triad to the original object is established, various and detailed "experiments" are carried out with the model, giving all the required qualitative and quantitative properties and characteristics of the object" (Samarski, Mikhailov, 2001).

The concept of model in science and technology has different meanings. Therefore, it is difficult to make a classification into types of modelling. Classification of modelling concepts is:

- by its nature;

- depending on the nature of the simulated object;

- depending on the places of modelling used (in engineering, physical science, chemistry and psychology, pedagogy of modelling processes).

Any classification of modelling techniques is conducted on the basis of scientific experience. It doesn't have a standard pattern. If the geometric, physical, functional properties of the studied objects are studied, then modelling is a specific modelling. For example, the modelling properties of the structure 
are used in the study of various mechanisms, vehicles. If the nature of the simulated object is only physical, then such modelling is called physical modelling. The physical nature of phenomena can also be studied empirically. It can be characterized by the mathematical relation of the simulated phenomena. For example, mechanical and electrical oscillations characterize only one differential equation. Therefore, mechanical oscillations can be investigated by means of electrical oscillations and Vice versa by means of mechanical oscillations. And it is very convenient for laboratory research. In this case, it is possible to measure unknown quantities.

According to authors' opinion, the process of mathematical modelling consists of three stages:

- first-stage - creating a mathematical model is the process of transition from a real area to a model area through formalization; an approximate description of any processes or phenomena expressed using mathematical symbols; this is usually a specific sequence of mathematical and logical operations called a program;

- second stage - solving mathematical problems in the framework of the constructed model;

- third stage - translating the result into practice-interpreting the results in the real area.

When analysing mathematical modelling, there is a deep understanding of the nature of the phenomena being studied. The connections connecting the main objects of the model are revealed. Here the facts related to the phenomena under consideration are revealed, and the relations between model objects are written in a mathematical term. Next, the authors study mathematical problems constructed using the model. Complex mathematical problems are solved using computer technologies. The calculation is performed according to the program on electronic computers. Mathematical modelling, which reduces the study of various processes and phenomena to mathematical problems, in connection with the advent of computers has become widely used.

Under the visibility most often understand the use of the didactic principle of visibility, when training is based on specific memorable images and examples, directly perceived by students. Recently, the use of special and technical means of training, such as audio-visual, multimedia, computer, has become increasingly understood as visibility in the classroom. During learning process visibility is understood as a specially organized demonstration of material to facilitate its understanding and consolidation through the use of simplified schemes, vivid images, memorable comparisons.

The principle of visibility in general is very important in teaching. The methods that use it are perhaps the oldest methods of learning and have been used since people began to transfer knowledge to each other. They are much more widely used in the technical Sciences, where the subject of study are material objects and processes, in themselves the use of visibility makes the training material more accessible, understandable and memorable, facilitating the learning process.

Mathematical modelling of practical problems develops the subject competence of the student. That is, develops independent productive thinking, intelligence. The authors show mathematical modelling of practical problems. One of the ways of mathematical development is the external way. He was born because of the need to solve problems outside of mathematics. In this case, the main reason for the development of mathematics is the solution of practical problems (counting objects, measuring area and volume, problems of Economics, technology, etc.).

In the second method, the construction of the theory and development of this theory depending on its internal laws is carried out on the basis of systematization, generalization of the discovered mathematical facts. These ways of development of mathematics are inextricably linked with each other. They are called, respectively, as the path of applied external and internal theory.

Thus, applied mathematics is the science of solving mathematical problems caused outside of mathematics. The peculiarity of solving applied problems is that their solution uses not only inductive analysis and deductive logic, but also an analysis that corresponds to reality, based on analogy and quantitative or physical experiments (Blehman, Mishkis, Ganovko, 2006).

Experiment plays an important role in solving applied problems. The experiment is often used in the construction of a mathematical model and shows the correctness of the chosen, used mathematical theory. For example, an equation constructed according to the content of applied problems is its 
analytical model, a drawing is a geometric model. The following is an example in Figure 1, that shows a geometric model of the function $y=x^{4}-x^{2}$. This is a parabola.

The graphic method occupies an important place in the school mathematics course. This method will help to find the approximate value of the desired value.

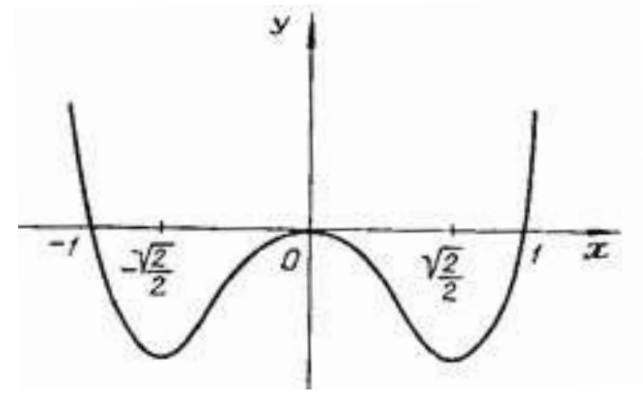

Figure 1. Geometric model of the function $y=x^{4}-x^{2}$.

In algebra, this method is often used to find solutions to equations and inequalities and their systems, to find the roots of quadratic equations. In geometry, it is used when constructing a square equal to a given square, when dividing an angle into equal parts.

The following is the repetition of theoretical material in the classroom.

Teacher: What are the stages of solving practical problems using mathematical modelling?

Student: The solution of applied problems consists of three stages.

The first stage of mathematical modelling is the translation of the problem condition into the language of mathematical formulas (equation, inequality). The second stage - the solution of the mathematical tasks within the constructed model. The third stage is the translation of the result into practice (interpretation stage).

The first stage: setting the problem.

Teacher: How can I conduct a lesson on "the System with two second-order unknowns" method of problem learning?

Student: The problem situation can be put in the form of a task.

Teacher: Well. Let's create a problem for studying this topic using the following geometric task.

The task: The Hypotenuse of a right triangle is $10 \mathrm{~cm}$, and the sum of the catheters is $14 \mathrm{~cm}$. Find the area of this triangle.

Decision. The first stage: creation of a mathematical model, i.e. translation of the content of a given problem into the language of a mathematical formula. Students in solving this applied problem developed its mathematical model.

Let $x$ and $y$ are the catheters of this right triangle. By the condition of problem, the hypotenuse $10(\mathrm{~cm})$ and $x+y=14(\mathrm{~cm})$. Then by the Pythagorean Theorem:

$$
\left\{\begin{array}{l}
x^{2}+y^{2}=10^{2} \\
x+y=14
\end{array}\right.
$$

where $x$ - the catheter one; $y$ - the catheter two.

So, a mathematical model of this practical problem has been created in the form of a system of two equations with two second-order unknowns (Formula 1).

The second stage: solving mathematical problem (Formulas 2,3,4).

$$
\left\{\begin{array}{l}
(14-y)^{2}+y^{2}=10^{2} \\
x=14-y
\end{array}\right.
$$




$$
\begin{aligned}
& \left\{\begin{array}{l}
196-28 y+y^{2}+y^{2}=10^{2} \\
x=14-y
\end{array}\right. \\
& \left\{\begin{array} { l } 
{ y ^ { 2 } - 1 4 y + 4 8 = 1 0 0 } \\
{ x = 1 4 - y }
\end{array} \Rightarrow \left\{\begin{array}{l}
y=8 \\
x=6
\end{array}\right.\right.
\end{aligned}
$$

The system is solved by the substitution method.

The area of the triangle is calculated by the following formula:

$$
S_{\Delta}=\frac{1}{2} a \cdot h_{a}=\frac{1}{2} b \cdot h_{b}=\frac{1}{2} c \cdot h_{c}
$$

The Triangle is rectangular. Therefore, $x=a=h_{b} ; y=b=h_{a}$. Substitute the values of $\mathrm{x}$ and $\mathrm{y}$ in the formula (5).

$$
S_{\Delta}=\frac{1}{2} a \cdot h_{a}=\frac{1}{2} x \cdot y=\frac{1}{2} \cdot 8 \cdot 6=24\left(\mathrm{~cm}^{2}\right)
$$

The solution of the geometric problem by the method of mathematical modelling led to the solution of a system of two equations with two second-order unknowns, which is solved by the substitution method.

The third stage: interpretation stage.

The catheters of the rectangular triangle are $8 \mathrm{~cm}, 6 \mathrm{~cm}$. The area of this triangle is $24 \mathrm{~cm}^{2}$ (Formula 6). What was required to find.

In the practical lessons of the course Methods of Teaching Mathematics, the solution of a system of two equations with two second-order unknowns was considered by the substitution method. Solving applied problems, drawing up its mathematical model develops cognitive abilities and mathematical thinking. The various formulas, tables, diagrams, schemes, equations and inequalities and their systems are used to model the problem. An important role is played by the development of students' ability to solve problems at all levels of education at school and in higher education institutions.

One of the effective ways to stimulate students and improve the quality of education is a rating system. The rating control system takes into account all active activities of students. This is due to the formation of methodical competence. The rating number of points is formed based on the results of such types of control as: 1) Entrance control-control of students ' knowledge and skills at the beginning of the course; 2) Current control; 3) Control of students ' knowledge and skills at the end of studying a topic or module; 4) Final control; 5) Control of residual knowledge and skills.

Because the rating is a student achievement scale, a well-designed and thought-out test is a standard measurement tool. To achieve certain quantitative results, the student plans and models his work. This prepares them for future professional work and forms methodical competence. That is why the authors conducted preparatory work at the Institute so that students could master the methodical competence and use it in their future school practice.

The formation of the methodical competence of the prospective mathematics teacher is a priority task of the pedagogical University, since the quality of training and education directly depends on the ability to organize all types of professional and pedagogical activities methodically correctly.

\section{Conclusions}

The necessity of using mathematical modelling as a method of forming the methodical competence of a prospective teacher is substantiated in this article. Methodical competence is the main component of teacher professional competence. It is known that professional competence is manifested by teachers with experience, but individual components are formed in the learning process at a pedagogical university.

On the basis of theoretical analysis domestic and foreign literature the authors defined the following:

- the essence of the concept of methodical competence means the personal and professional qualities that allows teacher to achieve a methodical result, her/his-theoretical and practical readiness to teach the subject and to use the knowledge of modern pedagogical technologies; 
- the concept of mathematical modelling means a method of qualitative and quantitative description of the process using a mathematical model that describes the real process using an adequate mathematical apparatus.

At the present stage, modelling as a method of scientific knowledge begins to play an increasingly important role. In fact, any method of scientific research, both theoretical and experimental, is based on the method of modelling. Models allowed to understand the device of various objects, to learn to manage them, to predict the consequences of impact on the object. This reveals the unity of the surrounding world and the method of modelling as a method of knowledge.

In order to form the methodical competence of students, it is shown:

- the usage of mathematical modelling technology in practical classes of the course Methods of teaching mathematics;

- the construction of a geometric model of the function $y=x^{4}-x^{2}$;

- the usage a problem-based learning method for solving a geometric problem using mathematical modelling on the example of organizing a lesson on the topic The System with two second-order unknowns.

Solving practical problems using mathematical modelling in theoretical and practical training of students has formed students' skills of preliminary modelling using cogitative orientation.

The method of mathematical modelling prepares the prospective teacher for teaching mathematics at school in combination with life and forms the ability to apply the obtained mathematical knowledge in practice. Mastering the method of mathematical modelling served as an indicator of students' readiness for future teaching activities. The results of pedagogical experience showed high-quality assimilation of educational material by students, development of independent productive thinking and intelligence of students of pedagogical University.

Thus, the method of using mathematical modelling as a means of forming the methodical competence of a prospective mathematics' teacher has been developed.

\section{Bibliography}

1. Bernander S., Szydlik J.E., Seaman C.E. (2020). Fostering and Modelling the Common Core Standards for Mathematical Practice in Content Courses for Prospective Elementary Teachers. In A. Appova, R.M. Welder, Z. Feldman, (Eds.), Supporting Mathematics Teacher Educators' Knowledge and Practices for Teaching Content to Prospective (Grades K-8) Teachers. Special Issue: Mathematics Enthusiast, 17(2,3), 907-937. Retrieved from https://scholarworks.umt.edu/tme/vol17/iss2/18

2. Blehman I.I., Mishkis A.D., Ganovko N.G. (2006). Mehanika I prikladnaja matematika: logika I osobennosti prikladnoi matematiki [Applied mathematics: Subject, logic, features of approaches] ( $2^{\text {nd }}$ ed.). Moskva: Nauka. Fizmatlit. (in Russian)

3. Boud D., Molloy E. (Eds.). (2013). Feedback in higher and professional education: understanding it and doing it well. London: Routledge.

4. Briede B., Krastina L. (2006). Competence Research Aspects, Kinds and Components. Journal of Science Education, 7(1), 20-22.

5. Briede B., Pēks L. (2014). A constructivist approach in teaching in higher education for getting methodological and reflection competences. In V. Dislere (Ed.), The Proceedings of the International Scientific Conference Rural Environment. Education. Personality (REEP), 7. Jelgava: LLU, 84-89. Retrieved from https://llufb.llu.lv/conference/REEP/2014/Latvia-UnivAgricult-REEP-2014proceedings-84-89.pdf

6. Cooke R.L. (2013). The history of mathematics a brief course ( $3^{\text {rd }}$ ed.). Hoboken, New Jersey: John Wiley \& Sons. Retrieved from http://www.maths.sci.ku.ac.th/suchai/02731141/hmath.pdf

7. Hernandez-Martinez P., Thomas S., Viirman O., Rogovchenko Y. (2019). "I'm still making dots for them": mathematics lecturers' views on their mathematical modelling practices. International Journal of Mathematical Education in Science and Technology, 50. doi: 10.1080/0020739X.2019.1668977 
8. Jackson B., Hauk S., Tsay J.J., Ramirez A. (2020). Professional Development for Mathematics Teacher Educators: Need and Design. Mathematics Enthusiast, 17(2,3), 537-582. Retrieved from https://scholarworks.umt.edu/tme/vol17/iss2/8

9. Jung H., Stehr E.M., He J. (2019). Mathematical modelling opportunities reported by secondary mathematics preservice teachers and instructors. School Science and Mathematics, 119(6), 353-365. doi: 10.1111/ssm.12359

10. Kaskatayeva B.R. (2009). Formation the Research Competence of Future Mathematics Teachers. Monograph. Almaty: Kazakh State Womens Teacher Training University.

11. Kaskatayeva B. (2014). Pedagogical conditions for forming the research competency in future teachers of mathematics. In V. Dislere (Ed.), The Proceedings of the International Scientific Conference Rural Environment. Education. Personality (REEP), 7. Jelgava, LLU, 103-109. Retrieved from https://llufb.llu.lv/conference/REEP/2014/Latvia-Univ-Agricult-REEP2014proceedings-103-109.pdf

12. Kaskatayeva B. (2017). Interactive Methods as the Way of Forming the Research Competence of Future Math Teachers. In V. Dislere (Ed.), The Proceedings of the International Scientific Conference Rural Environment. Education. Personality (REEP), 10. Jelgava, LLU, 284-291. Retrieved from https://lufb.llu.lv/conference/REEP/2017/Latvia-Univ-Agricult-REEP2017_proceedings-284-291.pdf

13. Kaskatayeva B.R. (2018a). Application of interactive methods in the course of the methodology of teaching mathematics. In International research symposium on Turkic world, 5(2). Almaty: Қазақ Мемлекеттік Қыздар Педагогикалық Университеті, 74-81. Retrieved from http://kazmkpu.kz/symposium/wp-content/uploads/2018/04/2-TOМ-9-КАЗАН-2018-СОНГЫ-1.pdf

14. Kaskatayeva B.R. (2018b). Bolashaq matematika mugalimderinin' a'distemelik quzirettiligin qalyptastyry' [Formation of methodical competence of the prospective teacher of mathematics]. Monograph. Almaty: Women's University. (in Kazakh)

15. Kaskatayeva B., Andassova M., Andassov M. (2018). Forming of Research Competence of Students on the Basis of Information Technologies. In V. Dislere (Ed.), The Proceedings of the International Scientific Conference Rural Environment. Education. Personality (REEP), 11. Jelgava, LLU, 179-185. doi: 10.22616/REEP.2018.021

16. Lyon J.A., Magana A.J. (2020). A Review of Mathematical Modelling in Engineering Education. International Journal of Engineering Education, 36(1A), 101-116.

17. Réveillac J.M. (2015). Optimisation Tools for Logistics. UK: Elsevier Ltd. Retrieved from https://www.sciencedirect.com/topics/engineering/linear-programming

18. Sala G., Font V. (2019). The role of modelling in an experience of inquiry-based mathematics teaching. Avances de Investigacion en Educacion Matematica, 16, 73-85. Retrieved from https://www.aiem.es/index.php/aiem/article/view/283 (in Spanish)

19. Samarski A.A., Mikhailov A.P. (2001). Matematiceskoje modelirovanije. Ideji, metodi, primeri [Mathematical modelling. Ideas. Methods. Examples]. Moskva: Fizmatlit (in Russian)

20. State program of education development of the Republic of Kazakhstan for 2011-2020. (2010). Astana: The Ministry of Education and Science of the Republic of Kazakhstan. Retrieved from https://kaznmu.kz/eng/wp-content/uploads/2012/01/program_2020_english.doc

21. Tang S.Y.F., Wong A.K.Y., Cheng M.M.H. (2015). The Preparation of Highly Motivated and Professionally Competent Teachers in Initial Teacher Education. Journal of Education for Teaching: International Research and Pedagogy, 41(2), 1-17. doi: 10.1080/02607476.2015.1010875

22. Tran D., Nguyen D.T., Nguyen A.T.T., Nguyen G.N.T., Ta P.M. (2019). Bridging to mathematical modelling: Vietnamese students' response to different levels of authenticity in contextualized tasks. International Journal of Mathematical Education in Science and Technology, doi: 10.1080/0020739X.2019.1648890

23. Trede F., Macklin R., Bridges D. (2012). Professional identity development: a review of the higher education literature. Studies in Higher Education, 37(3), 365-384. doi: 10.1080/03075079.2010.521237 